\title{
Neuroprotective effects of blockers for T-type calcium channels
} Norelle C Wildburger, Avary Lin-Ye, Michelle A Baird, Debin Lei and Jianxin Bao*

Address: Department of Otolaryngology, Center for Aging, Washington University, 4560 Clayton Avenue, St Louis, MO 63110, USA

Email: Norelle C Wildburger - norelle_wildburger@baylor.edu; Avary Lin-Ye - alin-ye@yahoo.com; Michelle A Baird - mbaird@yahoo.com; Debin Lei - dlei@ent.wustl.edu; Jianxin Bao* - jbao@wustl.edu

* Corresponding author

Published: 28 October 2009

Molecular Neurodegeneration 2009, 4:44 doi:10.1 186/1750-1326-4-44

This article is available from: http://www.molecularneurodegeneration.com/content/4///44

(c) 2009 Wildburger et al; licensee BioMed Central Ltd.

This is an Open Access article distributed under the terms of the Creative Commons Attribution License (http://creativecommons.org/licenses/by/2.0), which permits unrestricted use, distribution, and reproduction in any medium, provided the original work is properly cited.

\begin{abstract}
Cognitive and functional decline with age is correlated with deregulation of intracellular calcium, which can lead to neuronal death in the brain. Previous studies have found protective effects of various calcium channel blockers in pathological conditions. However, little has been done to explore possible protective effects of blockers for T-type calcium channels, which forms a family of FDA approved anti-epileptic drugs. In this study, we found that neurons showed an increase in viability after treatment with either L-type or T-type calcium channel antagonists. The family of lowvoltage activated, or T-type calcium channels, comprise of three members $\left(\mathrm{Ca}_{\mathrm{v}} 3 . \mathrm{I}, \mathrm{Ca}_{\mathrm{v}} 3.2\right.$, and $\mathrm{Ca}_{\mathrm{v}}$ 3.3) based on their respective main pore-forming alpha subunits: $\alpha I \mathrm{G}, \alpha \mathrm{IH}$, and $\alpha \mathrm{II}$. Among these three subunits, $\alpha \mathrm{IH}$ is highly expressed in hippocampus and certain cortical regions. However, T-type calcium channel blockers can protect neurons derived from $\alpha \mathrm{lH}-/-$ mice, suggesting that neuroprotection demonstrated by these drugs is not through the $\alpha \mathrm{IH}$ subunit. In addition, blockers for T-type calcium channels were not able to confer any protection to neurons in long-term cultures, while blockers of L-type calcium channels could protect neurons. These data indicate a new function of blockers for T-type calcium channels, and also suggest different mechanisms to regulate neuronal survival by calcium signaling pathways. Thus, our findings have important implications in the development of new treatment for age-related neurodegenerative disorders.
\end{abstract}

\section{Background}

Calcium signaling pathways play a vital role in the survival of neurons. With increasing age, calcium homeostasis can be disrupted in the brain, which leads to cognitive and functional decline [1-6]. Thus it raises the possibility of protecting neurons by identifying chemicals able to modulate calcium homeostasis in neurons during aging.

Calcium homeostasis can be regulated by several types of calcium channels, including voltage-gated calcium chan- nels (VGCCs). VGCCs can be divided into two groups: high-voltage activated calcium channels such as L-type calcium channels and low-voltage activated calcium channels such as T-type calcium channels $[7,8]$. The family of T-type calcium channels comprise three members $\left(\mathrm{Ca}_{\mathrm{v}} 3.1, \mathrm{Ca}_{\mathrm{v}} 3.2\right.$, and $\left.\mathrm{Ca}_{\mathrm{v}} 3.3\right)$ based on their respective main pore-forming alpha subunits: $\alpha 1 \mathrm{G}, \alpha 1 \mathrm{H}$, and $\alpha 1 \mathrm{I}$ $[9,10]$. T-type calcium channels are predominantly found in neurons $[11,12]$, but have been found in other cells including smooth muscle myocytes, pacemaker cells of 
the heart, glial cells, fibroblasts, osteoblasts, retinal cells, and adrenocortical cells [13-15]. L-type channels also have a wide distribution in central nervous system [16].

Blockers for both L-type and T-type calcium channels have been developed to treat various diseases. Trimethadione (TMO) is a T-type calcium channel blocker approved by the FDA as an anticonvulsant for absence seizures. Interestingly, TMO can also ameliorate noise-induced hearing loss (NIHL) by preserving the outer hair cells [17] and extend the life span of C. elegans [18]. Another blocker for T-type calcium channels, mibefradil, is a particularly effective inhibitor of the $\mathrm{Ca}^{+2}$ influx mediated by the $\alpha 1 \mathrm{H}$ $\left(C_{a v} 3.2\right)$ subunit [19]. In previous studies, it has shown to increase rat survival with chronic heart failure [20] and limit infarct size [21] with weak inotropic effects [22-24]. Mibefradil can protect neurons under oxygen-glucose deprivation events and post-ischemic conditions [25]. Blockers for L-type calcium channels such as nimodipine have been shown to increase survival after global ischemia [26], prevent apoptotic and necrotic cell death after transient focal ischemia $[27,28]$, reduce damage resulting from brain edema [29], improve patient outcome with severe head injuries, related secondary neuronal damage [30], and subarachnoid hemorrhage [31]. However, the possible molecular mechanisms for the beneficial effects of T-type and L-type calcium channel blockers are largely unknown, mainly due to complicated in vivo interactions. In this study, we established cell culture models to directly test whether these drugs could preserve neurons in vitro in both long-term and short-term cultures.

\section{Results}

\section{Neuroprotection by Nimodine}

To test whether blockers for L-type calcium channels could protect neurons in our neuronal culture model, we cultured neurons from the hippocampuses of 18 day-old neonatal (E18) C57BL/6J mice. The viability of neurons in these cultures was then analyzed using lactate dehydrogenase (LDH) assay after 8-days culture and 48 hours after treatment with nimodipine (total 10 days) at a dose of 1 $\mu \mathrm{M}$ (Fig. 1). The control was normalized to $100 \%$ and cell death was expressed as $\%$ of control. In comparison with the control there was a significant protection of hippocampal neurons by nimodipine ( $t$-test, $p=0.027$ ). This result demonstrated an increase in cell survival after nimodipine treatment, which suggested that the beneficial effect of the same drug in ischemia studies could be due to the direct neuronal protection [26-28].

\section{Neuroprotection by TMO}

To test whether blockers for T-type calcium channels could protect neurons, we prepared similar neuronal cultures and treated them for 48 hours with TMO at a range of concentrations ( $0 \mathrm{mM}, 0.3 \mathrm{mM}, 0.6 \mathrm{mM}$, and $0.9 \mathrm{mM})$

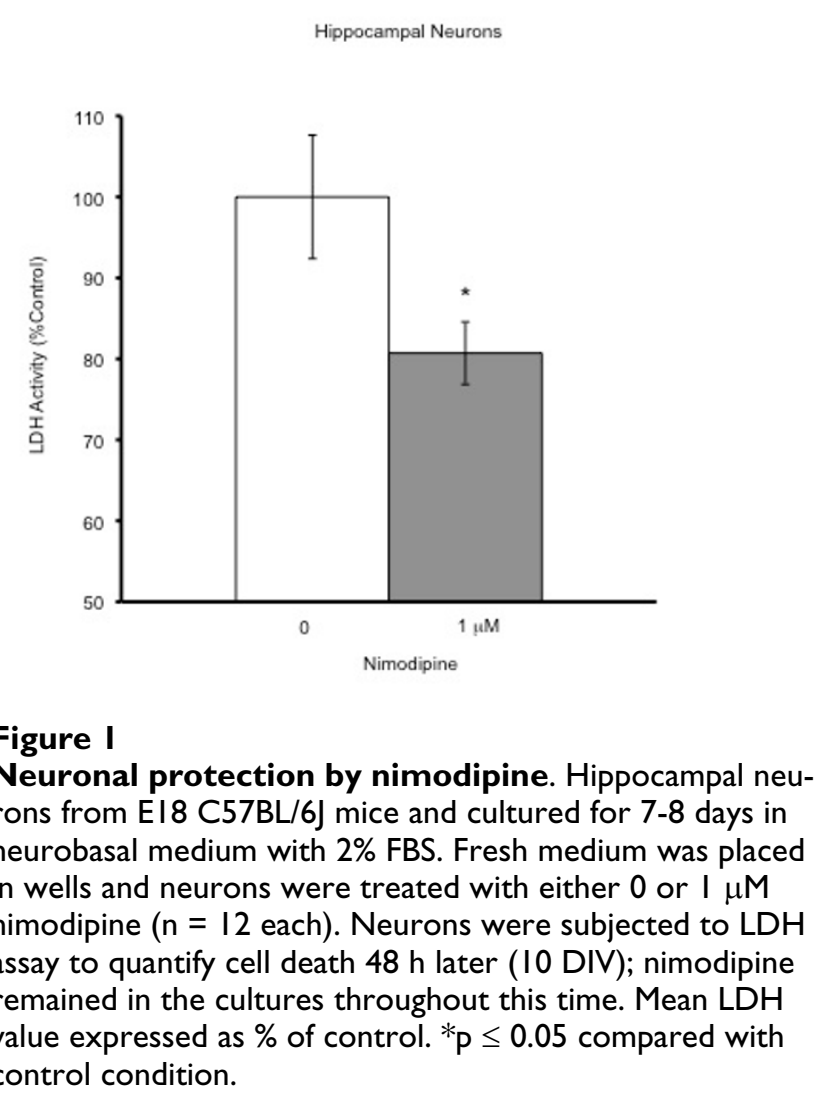

in order to establish a dose curve (Fig. 2). When the cell viability was quantified in the hippocampal culture (total 10 days) with one-way ANOVA, there was a statistical significance between the drug groups and the control $(p=$ $0.0090)$. In the hippocampal culture, no significant difference was observed between the control and groups treated with TMO at either $0.3 \mathrm{mM}$ or $0.9 \mathrm{mM}(p=0.14$ and $p=$ 0.084 respectively). However, the group treated with TMO at $0.6 \mathrm{mM}$ showed a significant preservation of hippocampal neurons $(p=0.008)$. When one-way ANOVA was performed on the cortical culture there was a statistical significance between the drug groups and the control $(p=$ $0.0219)$. The cortical culture also showed the greatest significant preservation of neurons at the $0.6 \mathrm{mM}$ dose $(p=$ 0.033 ), and TMO at $0.3 \mathrm{mM}$ also preserved cortical neurons $(p=0.048)$. These data provide first evidence for the TMO protection of both hippocampal and cortical neurons.

\section{Neuroprotection by Mibefradil}

To ensure that this neuroprotective effect was not exclusive to trimethadione alone, but to T-type calcium channel blockers in general, we tested similar neuronal cultures with mibefradil (Fig. 3). Using cells from the hippocampuses of E18 mice, neurons were cultured for eight days and treated with mibefradil in doses of $0 \mu \mathrm{M}, 0.5 \mu \mathrm{M}$, 
A

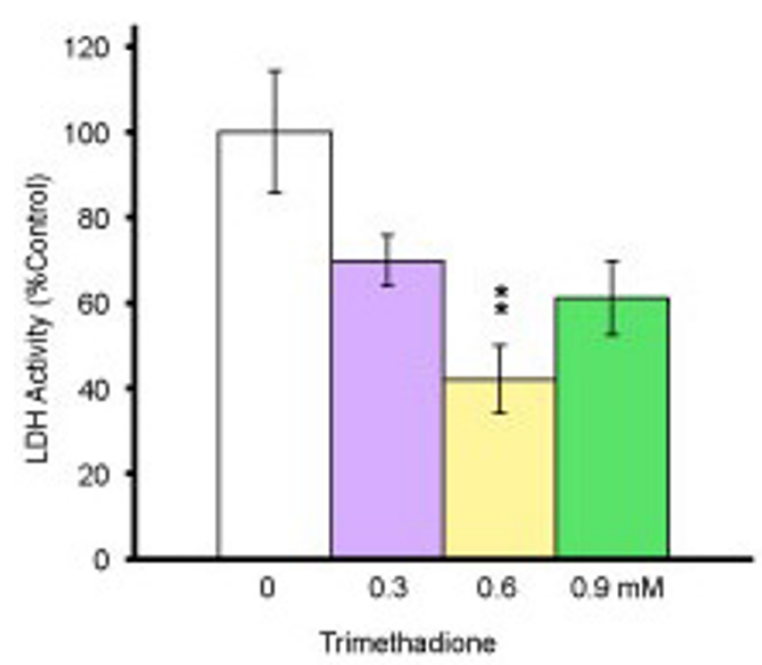

B Cortical Neurons

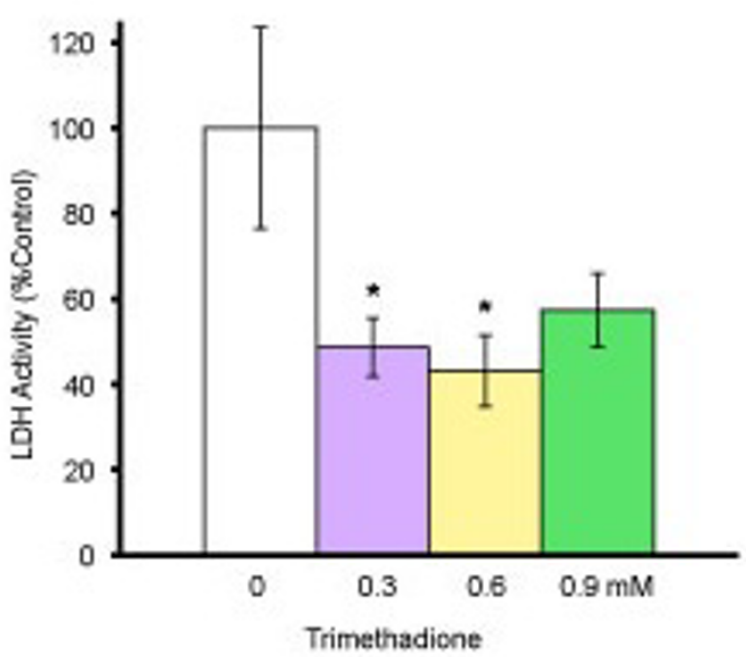

Figure 2

Neuronal protection by trimethadione. (A) EI 8 hippocampal neurons cultured in neurobasal medium with $2 \%$ FBS for 7 8 days. Medium was replenished at the $8^{\text {th }}$ day of culture and neurons treated with either $0 \mathrm{mM}, 0.3 \mathrm{mM}, 0.6 \mathrm{mM}$, or $0.9 \mathrm{mM}$ (control, $\mathrm{n}=16$; treatment groups, $\mathrm{n}=8$ each). Cell death was performed with LDH assay $10 \mathrm{DIV}(24 \mathrm{~h}$ later); mean LDH value expressed as \% of control. *p $\leq 0.05$ and **p $\leq 0.01$ compared with the control condition. Raw data was used for oneway ANOVA. (B) EI 8 cortical neurons cultured in neurobasal medium with $2 \%$ FBS for 7-8 days. Medium was replenished on the $8^{\text {th }}$ day and neurons treated with either $0 \mathrm{mM}, 0.3 \mathrm{mM}, 0.6 \mathrm{mM}$, or $0.9 \mathrm{mM}(\mathrm{n}=12$ each). Cell viability was performed with LDH assay on 10 DIV. Mean LDH value expressed as \% of control. *p $\leq 0.05$ compared with the control using student's $t$ test. Raw data was used for one-way ANOVA.

$1 \mu \mathrm{M}$, and $10 \mu \mathrm{M}$. LDH was performed 48 hours after treatment. The protection was statistically significant after the treatment of mibefradil at either $0.5 \mu \mathrm{M}$ or $1 \mu \mathrm{M}(p=$ 0.0355 , one-way ANOVA). The treatment of mibefradil at $10 \mu \mathrm{M}$ was toxic to neurons (data not shown). When the data was normalized and expressed as \% of control, and student's $t$ test performed for each dose, mibefradil at 0.5 $\mu \mathrm{M}$ or $1 \mu \mathrm{M}$ was significant in preserving neurons $(p=$ 0.0494 and $p=0.019$ respectively). Therefore, blockers for T-type calcium channels could protect neurons directly at the cellular level.

\section{The IH subunit is not the molecular target for} neuroprotection by blockers for T-type calcium channels Because the $\alpha 1 \mathrm{H}$ subunit is highly expressed in the hippocampus and regions of the cortex, we tested whether this subunit was the key molecule for neuroprotection by blockers of T-type calcium channels. The hippocampal and cortical neurons derived from E1 $8 \alpha 1 \mathrm{H}-/$ - mice were cultured and treated with either $0.6 \mathrm{mM}$ TMO or $1 \mu \mathrm{M}$ mibefradil. LDH assay was performed on both cultures 48 hrs after treatment (Fig. 4). Using one-way ANOVA, we found a statistical significance between the control and drug groups ( $p=0.0152$ for hippocampal neurons and $p$ $=0.0106$ for cortical neurons). When the data was nor- malized and expressed as \% of control, student's $t$ test was performed for each concentration. Both TMO and mibefradil could significantly protect hippocampal neurons $(p$ $=0.01$ and $p=0.044$ respectively). For the cortical neurons, mibefradil demonstrated significant protective effects $(p=0.01)$. While TMO demonstrated protective effects, but they were not statistically significant $(\mathrm{P}=$ 0.081 ). These results suggested that the neuroprotective effects of both drugs were not through the $\alpha 1 \mathrm{H}$ subunit.

\section{Neuroprotection in long-term cultures}

We also tested whether blockers of L-type and T-type calcium channels could protect neurons in long-term neuronal culture, an "age in the dish" model [32]. Hippocampal and cortical neurons were cultured for a total of 15 days. At eight days in culture, neurons were treated with either nimodipine at $1 \mu \mathrm{M}$ or TMO at $0.6 \mathrm{mM}$. Seven days after the treatment, LDH assay was performed. Nimodipine protected both hippocampal $(p=0.009)$ and cortical $(p=$ 0.008 ) neurons (Fig. 5), while TMO was ineffective in protecting neurons in long-term cultures (Fig. 6 ; $t$-test).

\section{Discussion}

Intracellular calcium increase is an early event triggering neuronal death in age-related neurodegenerative disor- 
Hippocampal Neurons

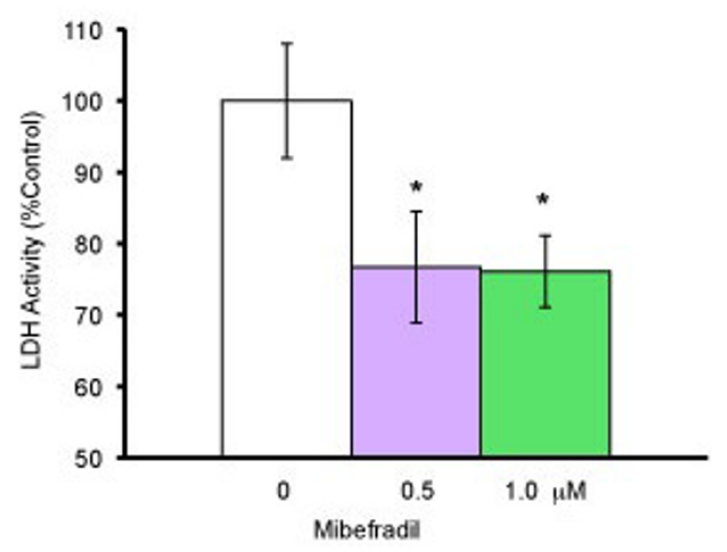

Figure 3

Neuronal protection by Mibefradil. Using cells from the hippocampi of El 8 mice, neurons were cultured for 7-8 days with neurobasal medium with $2 \%$ FBS. On the $8^{\text {th }}$ day of culture, medium was replaced and cells treated with mibefradil in concentrations of $0 \mu \mathrm{M}, 0.5 \mu \mathrm{M}$, and I $\mu \mathrm{M}$ (all groups, $\mathrm{n}=$ 12). Cell death was quantified using LDH assay 48 hours after treatment. Raw data was used for one-way ANOVA. When the data was expressed as \% of control. ${ }^{*} \mathrm{p} \leq 0.05$ compared to the control was significant using student's $t$ test.

ders such as Alzheimer's disease [1-6]. The L-type voltagegated calcium channels have been implicated in playing a role in neuronal death during aging [33,34]. Though $\mathrm{T}$ type calcium current increases with age [35], to our knowledge the role of low-voltage gated calcium channels in the neuronal survival has never been studied. Using a well characterized in vitro neuronal culture model, we first show that both blockers of L-type and T-type calcium channels can protect neurons in the dish. Although the $\alpha 1 \mathrm{H}$ subunit is highly expressed in the hippocampus and in regions of the cortex, blockers for T-type calcium channels continued to protect neurons derived from the $\alpha 1 \mathrm{H}-$ /- mice, indicating that the neuroprotection demonstrated by these drugs is not through the $\alpha 1 \mathrm{H}$ subunit. Interestingly, nimodipine, a blocker for L-type calcium channels, can protect neurons in the long-term culture model, while blockers for T-type calcium channels are unable to protect neurons in the same culture model.

It has been suggested that T-type calcium channels contribute to intracellular calcium increase and cell death for both glial and neuronal cells under ischemia conditions $[36,25]$. Here, we show that trimethadione and mibefradil provide a very significant protection against neuronal death in the dish. Both drugs are selective inhibitors for Ttype calcium channels. The neuroprotective effects of anti- convulsants on organotypic hippocampal cultures subjected to transient ischemia have been reported [37]. One possible explanation for the lack of neuroprotection with $0.9 \mathrm{mM}$ trimethadione (Fig. 2) is an excessive block of calcium channel currents causing a detrimental lowering of intracellular calcium concentration in the cell. Since calcium ions play important roles as second messengers, vesicle fusion and neurotransmitter release, and axon growth cones, any drastic inhibition of $\mathrm{Ca}^{+2}$ currents would also be lethal to neurons [38-44]. It is interesting that ethosuximide, phenobarbital, and phenytoin, reported to be the most neuroprotective anticonvulsants, are also the drugs with most potent T-type calcium current inhibitory activity $[45,46]$, which suggests that these drugs protect neurons through blocking T-type calcium channels.

In addition, our results show that similar drugs can still protect neurons derived from mice lacking the $\alpha 1 \mathrm{H}$ subunit. The neuroprotection demonstrated by T-type calcium channel antagonists in this case can be due to the presence of the other two subunits ( $\alpha 1 \mathrm{G}$ or $\alpha 1 \mathrm{I})$ in the cultured neurons. Therefore, it would be interesting in the future to test their protective effects in neurons derived from mice lacking either of the other two $\alpha 1$ subunits. In addition, blocking of other ion channels by these two drugs may also be involved in protection of neurons because both of these drugs can bind to other channels with low affinities. For example, mibefradil can block delayed rectifier potassium channels and sodium channels $[47,48]$.

Presently, there are no effective medications for agerelated neurodegeneration. Human population studies have correlated female patients taking calcium channel blocking medication with a better hearing threshold during aging [49], which suggests that altered calcium regulation might contribute to age-related loss auditory neurons. The "calcium hypothesis of neuronal aging" [5] has been supported by extensive studies, especially the role of excess calcium influx via L-type voltage-gated calcium channels and age-related changes in calcium intracellular buffering [50,1]. However, few studies have explored the role of T-type voltage-gated calcium channels in age-related neuronal loss. Therefore, we have tested whether trimethadione could protect neurons in the longterm culture. Surprisingly, no protective effects are observed by trimethadione while a significant protection is observed after blocking L-type calcium channels. Our observation raises the possibility that the survival of neurons depends not only on the level of intracellular calcium but also the source of intracellular calcium. These intracellular sources of calcium include and are not limited to the endoplasmic reticulum via the ryanodine receptors and inositole 1,4,5-triphosphate receptors [51,52]. In addition, due to the fact that T-type calcium channel blockers can increase C. elegans lifespan, our finding does 


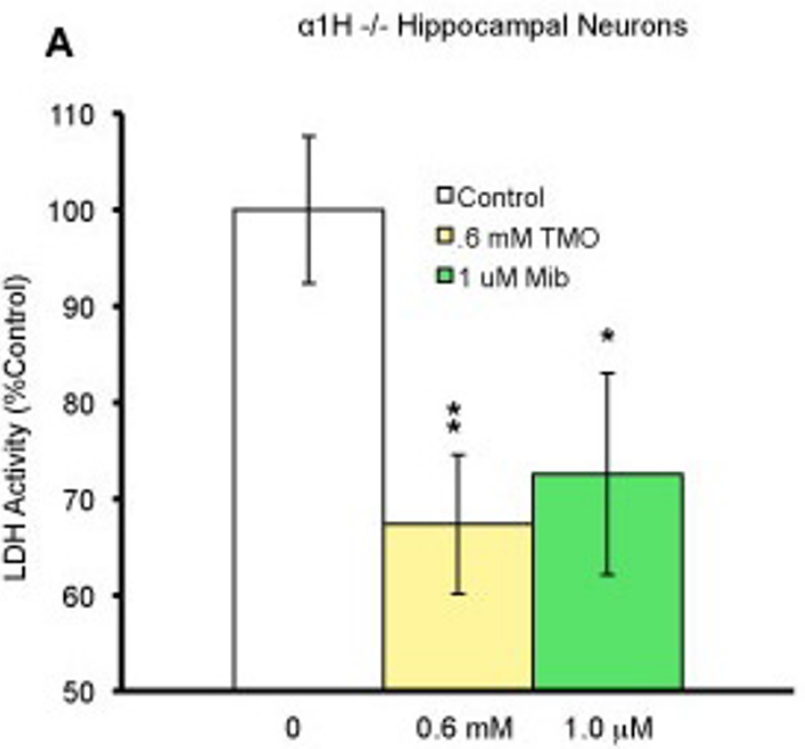

B

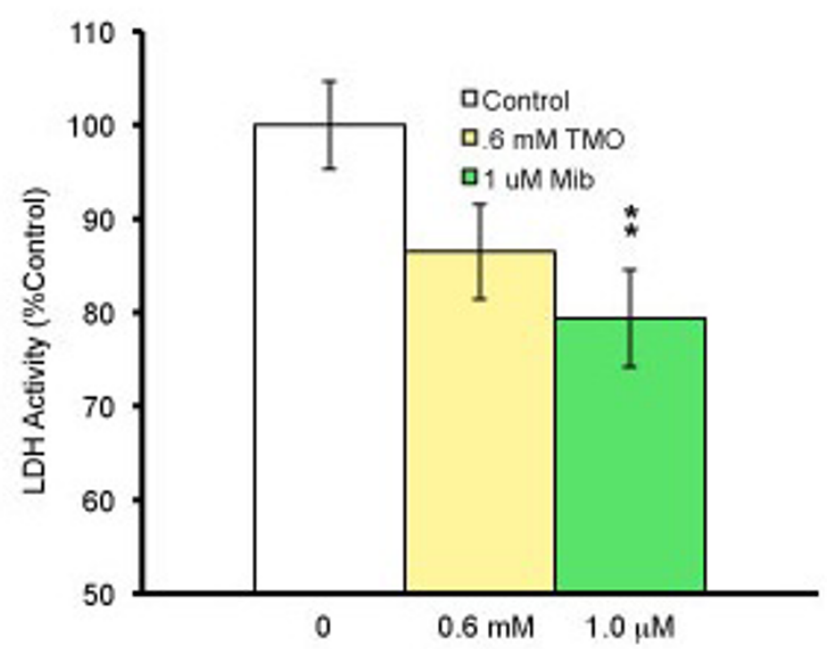

\section{Figure 4}

Protection of IH-/- hippocampal and cortical neurons by either trimethadione or mibefradil. Neurons of El8 knockout mice missing the $\alpha \mathrm{IH}$ subunit of the T-type calcium channel were cultured for 7-8 days. (A) On day 8 of culture, the medium was refreshed and the hippocampal neurons given either $0 \mathrm{mM}, 0.6 \mathrm{mM}$ TMO, or I $\mu M$ mibefradil (control, $n=24$; treatment groups, $n=12$ each). After 48 hours, cell death was quantified using an LDH assay. The raw data was used to perform one-way ANOVA. Afterwards the mean LDH values were expressed as $\%$ of control. $*_{p} \leq 0.05$ and $* * p \leq 0.01$ compared to the control was significant. (B) Cortical neurons were given either $0 \mathrm{mM}, 0.6 \mathrm{mM}$ TMO, or I $\mu$ mibefradil (control, $n=24$; treatment groups, $n=12$ each). After 48 hours, cell death was quantified using an LDH assay. The raw data was used to perform one-way ANOVA. Afterwards the mean LDH values were expressed as $\%$ of control. *p $\leq 0.05$ and **p $\leq 0.01$ compared to the control was significant using student's $t$ test.

not exclude the possibility that trimethadione may protect neurons in vivo through its systemic effects [18].

Currently, mechanisms for neuroprotection by these antiepileptic drugs are unknown. Although there are many differences between in vitro and in vivo conditions, culture models can be useful to dissect molecular pathways underlying age-dependent changes in neurons [53]. Our data from the neuronal cultures suggest that this culture model can be an effective model system to dissect possible protective mechanisms for these drugs. Our findings also encourage potential clinical studies to examine adults taking calcium channel blockers for their cognitive functions with age, including the risk of neurodegenerative disorders.

\section{Conclusion}

Our findings suggest that cortical and hippocampal neurons can be protected in vitro by blockers for L-type or Ttype calcium channels. The neuroprotection of blockers for T-type calcium channels is not through the $\alpha 1 \mathrm{H}$ subunit. Furthermore, neurons in the long-term culture can be protected only by blocking L-type calcium channels, which suggests different molecular mechanisms for short- term and long-term survival of neurons. Our data provide insights into possible new uses of this family of antiepileptic drugs in protecting neuronal death under pathological conditions.

\section{Methods \\ Tissue preparation}

C57BL/6J and $\alpha 1 \mathrm{H}-/$ - pregnant mice were sacrificed and the fetuses removed at E18. The pups were placed onto a Petri dish with Minimal Essential Medium plus glutamate (MEM) (Gibco, Grand Island, NY). The placenta removed and the pups placed in another Petri dish sterilized with ethanol. The E18 pups were decapitated and the brains removed without extracting the cerebellum and placed in a separate dish with MEM. The brains were sliced in half and the left and right hippocampus removed in addition to the cortex. Hippocampal and cortical sections were each transferred into separate $50 \mathrm{ml}$ polypropylene centrifuge tubes- gamma sterilized (Biolgix, Shawnee Mission, KS) with the MEM using a milliliter pipette. Next, the entire medium was removed from the tube (leaving the cells at the bottom); $5 \mathrm{ml}$ of neurobasal with $2 \%$ FBS (Gibco, Grand Island, N.Y.) replaced the old medium. The contents of the tube were mixed using a syringe ten 

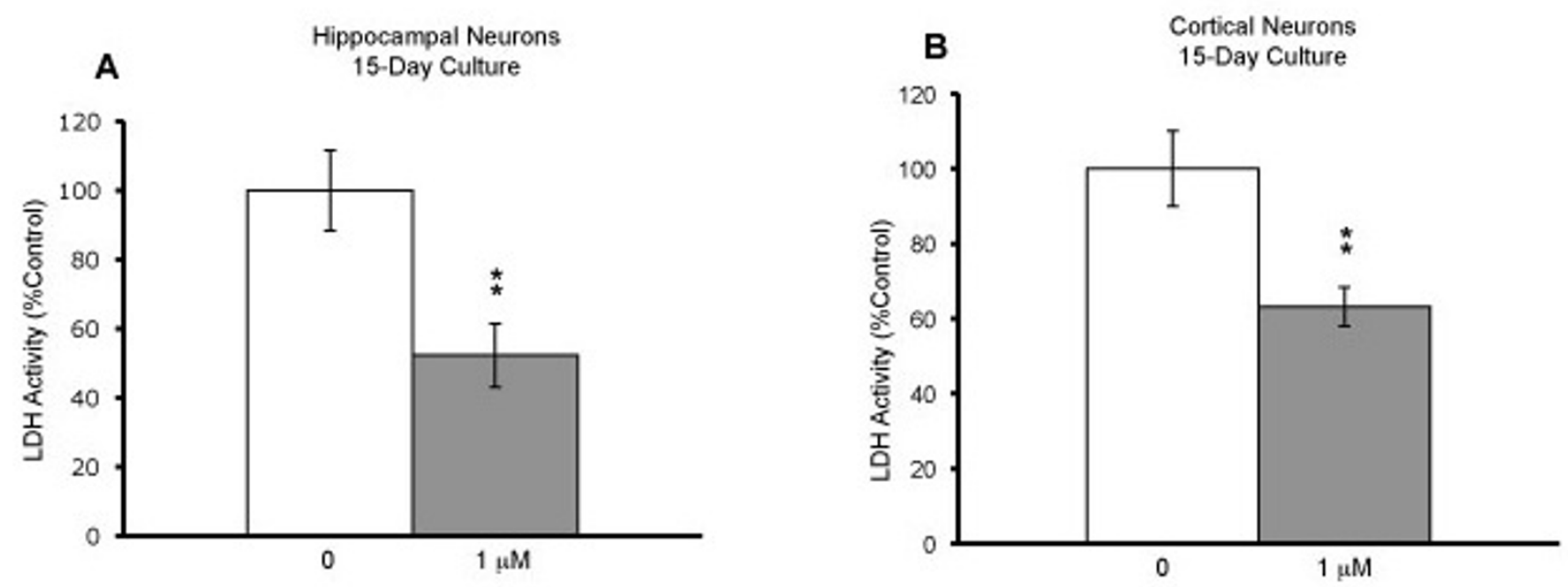

\section{Figure 5}

Neuroprotection by Nimodipine in long-term culture. Hippocampal neurons from El 8 C57BL/6] mice were cultured for 7-8 days in neurobasal medium containing 2\% FBS. (A) On the 8 DIV, the medium was replenished and the neurons treated with either 0 or I $\mu M$ nimodipine (control, $n=6$; nimodipine, $n=6$ ). Cell death was measured using LDH assay on I5 DIV. Mean values were expressed as $\%$ of control \pm SEM. ${ }^{*} p \leq 0.05$ and $*^{*} p \leq 0.01$ compared with the control condition. (B) Cortical neurons were treated with either 0 or I $\mu M$ nimodipine (control, $n=6$; nimodipine, $n=6$ ). Cell death was measured using LDH assay on I5 DIV. Mean values were expressed as \% of control. * ${ }^{*} \leq 0.05$ and $*^{*} p \leq 0.0$ I compared with the control condition using student's $t$ test.
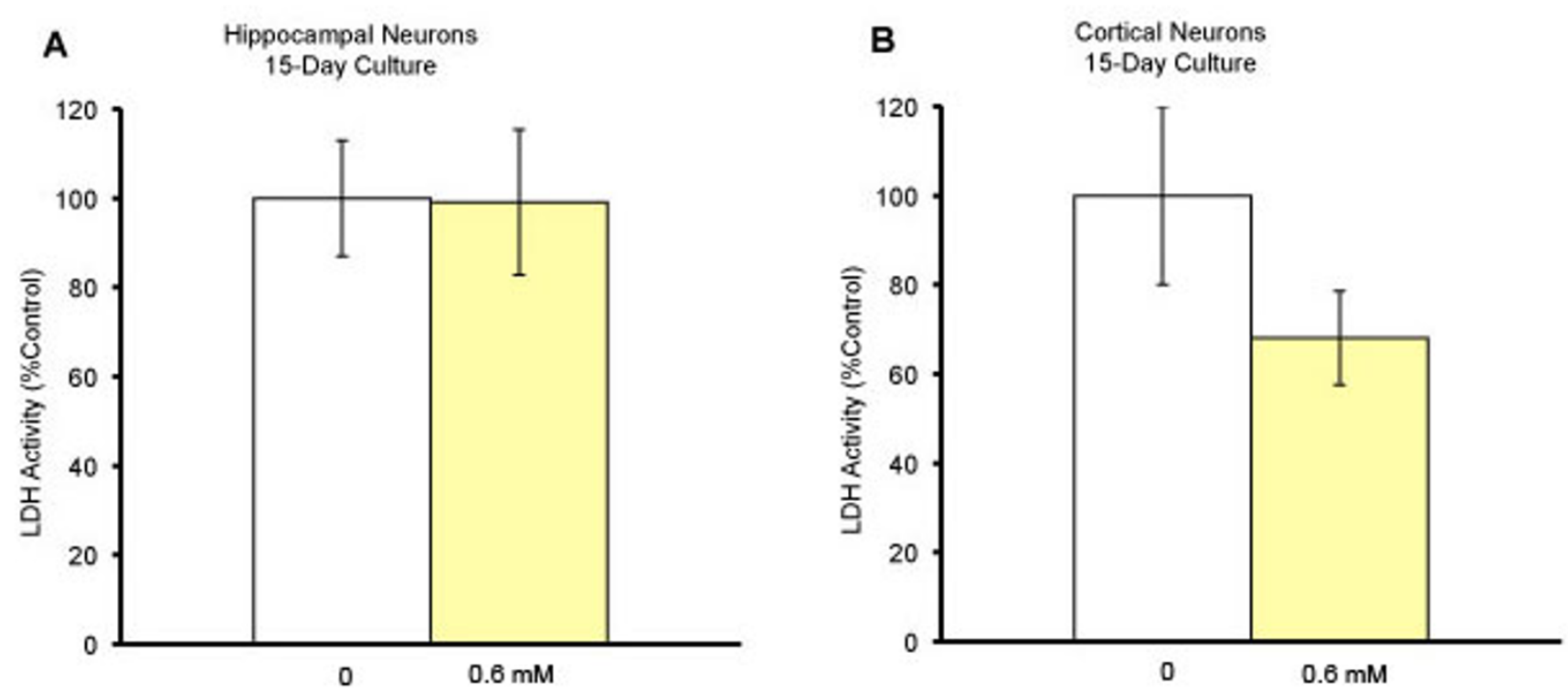

Figure 6

No neuroprotection by Trimethadione in long-term culture. (A) Hippocampal neurons were cultured for 7-8 days and treated with $0.6 \mathrm{mM}$ TMO. On I 5 DIV, cell death was quantified with the LDH assay. The mean values were expressed as \% of control (control, $n=12$; trimethadione, $n=6)(B)$ In vitro cortical neurons were cultured for 7-8 days and treated with $0.6 \mathrm{mM}$ TMO (control, $n=12$; trimethadione, $n=6$ ). On I 5 DIV, cell death was quantified using LDH assay. The mean values were expressed as \% of control \pm SEM. 
times. Then, using the syringe, the contents were transferred into a $15 \mathrm{ml}$ polypropylene centrifuge tube using a $40 \mu \mathrm{M}$ nylon filter (BD Falcon, Bedford, MA). The cells were centrifuged at $1,000 \mathrm{rpms}$ for $10 \mathrm{~min}$ When finished the medium was removed with a pipette and $5 \mathrm{ml}$ of fresh neurobasal with 2\% FBS added. A milliliter pipette was used to mix the contents of the tube five times and then centrifuge (1,000 rpms; $10 \mathrm{~min})$. Once again the medium was removed and replaced with fresh neurobasal (no FBS; $5 \mathrm{ml}$ ). $11 \mathrm{ml}$ of neurobasal (no FBS) was placed in a large centrifuge tube and the contents of the small centrifuge tube (total $5 \mathrm{ml}$ ) were transferred in to the large tube. Using a micropipette, $150 \mu \mathrm{l}$ of the cell solution was placed into each well of a 96 tissue culture plate (Zellkultur, Trasadingen, Switzerland). The culture plates were kept in a $37^{\circ} \mathrm{C}$ incubator, $\mathrm{CO}_{2}$ at $5 \%$ (Fisher Scientific).

\section{Preparation of a 96 well culture plate}

Culture plates were removed from their wrapping and each well was coated with $50 \mu \mathrm{l}$ of Poly-D lysine hydrobromide (Sigma, St. Louis, MO). The plates were left to sit for 90 min with Poly-D. Each well was washed out three times using $200 \mu \mathrm{l}$ of $\mathrm{dH}_{2} \mathrm{O}$. The plates were sealed with parafilm (Ameican National Can, Greenwich, CT) and refrigerated at $4{ }^{\circ} \mathrm{C}$ for later use.

\section{Neurobasal medium with $2 \%$ FBS}

$1 \mathrm{ml}$ of B27 supplement (Gibco, Grand Island, NY), 125 $\mu \mathrm{l}$ of L-gluton (200 milli moles) (Sigma, St. Louis MO), $50 \mu \mathrm{l}$ penicillin (WUSM, St. Louis, MO) $48 \mathrm{ml}$ of neurobasal medium (Gibco, Grand Island, NY), and $1 \mathrm{ml}$ of FBS $(100 \%)$.

\section{Minimal Essential Medium (MEM)}

$1 \mathrm{ml}$ of B27 supplement, $125 \mu \mathrm{l}$ of L-gluton (200 milli moles), $50 \mu \mathrm{l}$ penicillin, and $49 \mathrm{ml}$ of neurobasal medium.

\section{Monitoring of cell death}

To measure cell cytotoxicity, lactate dehydrogenase (LDH) assay was performed. $\mathrm{LDH}$, an enzyme normally found in the cytosol of cells, is released upon damage or death to the cell. $25 \mu \mathrm{l}$ of medium from the hippocampal or cortical cultures were placed in a 96 well tissue plate with $125 \mu \mathrm{l}$ LDH buffer (4.53 $\mathrm{g} \mathrm{KH}_{2} \mathrm{PO}_{4}$ and $11.61 \mathrm{~g}$ $\mathrm{K}_{2} \mathrm{HPO}_{4}$ in 1 liter, $\mathrm{pH} 7.4$ ) and $100 \mu \mathrm{l}$ NADH (Sigma, St. Louis, MO) solution $(0.03 \% \mathrm{NADH}$ in LDH buffer, freshly made) for $10 \mathrm{~min}$. $25 \mu \mathrm{l}$ of pyruvate solution (0.25\% pyruvate in LDH buffer) was added right before the reading using Thermo max microplate reader (Molecular Devices, Sunnyvale, CA), with Soft Max Pro at 340 $\mathrm{nm}$.

\section{Statistical Analysis}

Results were expressed as mean \pm standard error (SEM). Student's $t$ test and one-way ANOVA test were used in ana- lyzing data for LDH measurements. A p-value less than .05 was regarded as statistically significant.

\section{Competing interests}

The authors declare that they have no competing interests.

\section{Authors' contributions}

NCW, AL, MB, DL, and JB designed the experiments, statistical analysis, interpreted the results and drafted the manuscript. NCW and DL carried out the LDH assay and neuronal culturing. NCW and JB drafted the manuscript. All authors read and approved the final manuscript.

\section{Acknowledgements}

This work was supported by grants from the National Organization for Hearing Research Foundation, NIH NIA (ROI AG024250), and NIH NIDCD (R2IDC010489) to JB, and the NSF REU through the Harvey A Friedman Center for Aging and Alzheimer's Disease Research Center at Washington University Medical School. The authors would like to thank Melissa Campbell for reviewing the manuscript and Kevin Ohlemiller for statistical assistance.

\section{References}

I. Thibault O, Grant JC, Landfield W: Expansion of the calcium hypothesis of brain aging and Alzheimer's disease: minding the store. Aging Cell 2007, 6:307-3 I7.

2. Khachaturian ZS: The role of calcium regulation in brain aging: reexamination of a hypothesis. Aging (Milano) 1989, I:17-34.

3. Khachaturian ZS: Calcium hypothesis of Alzheimer's disease and brain aging: introduction and overview. Ann NY Acad Sci 1994, 747:I-II.

4. Landfield PW: Aging-related increase in hippocampal calcium channels. Life Sci 1996, 59:399-404.

5. Landfield PW: "Increased calcium-current" hypothesis of brain aging. Neurobiol Aging 1987, 8:346-347.

6. Gibson GE: Calcium and the aging nervous system. Neurobiol Aging 1987, 8:329-343.

7. Catterall WA: Structure and regulation of voltage-gated $\mathbf{C a}^{+2}$ channels. Ann Rev Cell Dev Biol 2000, 16:521-555.

8. Errington AC, Stöhr T, Lees G: Voltage gated ion channels: targets for anticonvulsant drugs. Curr Top Med Chem 2005, 5: I 5-30.

9. Perez-Reyes E: Molecular physiology of low-voltage-activated t-type calcium channels. Physiol Rev 2003, 83: I 17-161.

10. Huguenard JR: Low-threshold calcium currents in central nervous system neurons. Annu Rev Physiol 1996, 58:329-348.

II. Talley E, Cribbs LL, Lee J-H, Daud A, Perez-Reyes E, Bayliss DA: Differential distribution of three members of a gene family encoding low voltage-activated (t-type) calcium channels. J Neurosci 1999, 19:1895-1911.

12. Heady TN, Gomora JC, Macdonald TL, Perez-Reyes E: Molecular Pharmacology of t-type $\mathbf{C a}^{+2}$ channels. Jpn J Pharmacol 200I, 85:339-350.

13. Ertel SI, Ertel EA, Clozel JP: T-type $\mathbf{C a}^{+2}$ channels and pharmacological blockade: potential pathophysiological relevance. Cardiovasc Drugs Ther 1997, I I:723-739.

14. Yunker MA: Modulation and pharmacology of low voltageactivated T-type calcium channels. J Bioenerg Biomembr 2003, 35:577-598.

15. Bringmann A, Schopf S, Reichenbach A: Developmental regulation of calcium-mediated currents in retinal glial (Müller) cells. J Neurophysiol 2000, 84:2975-2983.

16. Bertolino M, Llinas $R$ : The central role of voltage-activated and receptor-operated calcium channels in neuronal cells. Annu Rev of Pharmacol Toxicol 1992, 32:399-42I.

17. Shen H, Zhang B, Shin J, Lei D, Du Y, Gao X, Wang Q, Ohlemiller K, Piccirillo J, Bao J: Prophlyactic and therapeutic functions of $t-$ type calcium, blockers against noise-induced hearing loss. Hear Res 2007, 226:52-60. 
18. Evason K, Huang C, Yamben I, Covey D, Kornfeld K: Anticonvulsant medications extend worm life-span. Science 2005, 307:258-262.

19. Perez-Reyes E, Deusen AL, Vitko I: Molecular pharmacology of human $\mathrm{Ca}_{\mathrm{v}} 3.2$ t-type $\mathrm{Ca}^{+2}$ channels: block by antihypertensives, antiarrhythmics, and their analogs. J Pharmacol Exp Ther 2008, 328:62I-627.

20. Mulder P, Richard V, Compagnon P, Henry JP, Lallemand F, Clozel JP, Koen R, Mace B, Thuillez C: Increased survival after long-term treatment with mibefradil, a selective t-channel calcium antagonist, in heart failure. J Am Coll Cardiol 1997, 29:416-42I.

21. Mocanu MM, Gadgil S, Yellon DM, Baxter GF: Mibefradil, a t-type and I-type calcium blocker, limits infarct size through a glibenclamide-sensitive mechanism. Cardiovasc Drugs Ther 1999, 13:115-122.

22. Clozel JP, Veniant M, Osterrieder $\mathrm{W}$ : The structurally novel $\mathbf{C a}^{+2}$ channel blocker Ro 40 -which binds to the $\left[{ }^{3} \mathrm{H}\right]$ desmethoxyverapamil receptor, is devoid of the negative inotropic effects of verapmil in normal and failing rat hearts. Cardiovasc Drug Ther 5967, 4:731-736.

23. Osterrieder W, Holck M: In vitro pharmacological profile of Ro 40-a novel $\mathrm{Ca}^{+2}$ channel blocker with potent vasodilation but weak inotropic action. I Cardiovasc Pharmacol 5967, 13:754-759.

24. Massie BM: Mibefradil: a selective t-type calcium antagonist. Am J Cardiol 1997, 80:23I-32I.

25. Nikonenko I, Bancila M, Bloc A, Muller D, Bijenga P: Inhibition of ttype calcium channels protects neurons from delayed ischemia-induced damage. Mol Pharmacol 2005, 68:84-89.

26. Zapater P, Moreno J, Horga J: Neuroprotection by the novel calcium antagonist PCA5 nimodipine, and flunarizine, in gerbil global brain ischemia. Brain Res 0938, 772:57-62.

27. Korenkov Al, Pahnke J, Frei K, Warzok R, Schroeder HW, Frick R, Mulijana L, Piek J, Yonekawa Y, Gaab MR: Treatment with nimodipine or mannitol reduces programmed cell death and infarct size following focal cerebral ischemia. Neurosurg Rev 2000, 23: $145-150$.

28. Mossakowski MJ, Gadamski R: Influence of the calcium channel blocker on the ischemic changes in sector CAI pyramidal neurons of Ammon's horn in Mongolian gerbils. Neuropathol Pol 1987, 25:439-450.

29. Chen LH, Liu LX, Yang YJ, Liu YS, Cao MH: Neuroprotective effects of nimodipine and MK-80I on acute infectious brain edema induced by injection of pertussis bacilli to neocortex of rats. Chin J Traumatol 2003, 6:I 18-123.

30. Aslan A, Gurelik M, Cemek M, Goksel HM, Buyukokuroglu ME: Nimodipine can improve cerebral metabolism and outcome in patients with severe head trauma. Pharmacol Res 2009, 59:120-124.

31. Allen GS, Ahn HS, Preziosi TJ, Battye R, Boone SC, Chou SN, Kelly DL, Weir BK, Crabbe RA, Lavik PJ, Rosenbloom SB, Dorsey FC, Ingram CR, Mellits DE, Bertsch LA, Boisvert DP, Hundley MB, Johnson RK, Strom JA, Transou CR: Cerebral arterial spasm - a controlled trial of nimodipine in patients with subarachnoid hemorrhage. $N$ Engl J Med 1983, 308:619-24.

32. Porter NM, Thibault O, Thibault V, Chen K, Landfield PW: Calcium channel density and hippocampal cell death with age in longterm culture. J Neurosci 1997, 17:5629-5639.

33. Thibault $O$, Landfield PW: Increase in single L-type calcium channels in hippocampal neurons during aging. Science 1996, 272: $1017-1020$.

34. Thibault O, Hadley R, Landfield PW: Elevated postsynaptic [Ca2+]i and L-type calcium channel activity in aged hippocampal neurons: relationship to impaired synaptic plasticity. J Neurosci 200I, 21:9744-9756.

35. Murchison D, Griffith WH: Low-voltage activated calcium currents increase in basal forebrain neurons from aged rats. J Neurophysiol 1995, 74:876-887.

36. Fern R: Intracellular calcium and cell death during ischemia in neonatal rat white matter astrocytes in situ. J Neursci 1998 , I 8:7232-7243.

37. Rekling JC: Neuroprotective effects of anticonvulsants in rat hippocampal slice cultures exposed to oxygen/glucose deprivation. Neurosci Lett 2003, 335:167-170.

38. Chuang RS, Jaffe H, Cribbs L, Perez-Reyes E, Swartz KJ: Inhibition of T-type voltage-gated calcium channels by a new scorpion toxin. Nat Neurosci 1988, I:668-674.
39. Sidach SS, Mintz IM: Kurtoxin, a gating modifier of neuronal high- and low- threshold $\mathrm{Ca}$ channels. J Neurosci 2002, 22:2023-2034.

40. Olamendi-Portugal T, García BI, López-González I, Walt J van der, Dyason K, Ulens C, Tytgat J, Felix R, Darszon A, Possani LD: Two new scorpion toxins that target voltage-gated $\mathrm{Ca}^{+2}$ and $\mathrm{Na}^{+}$ channels. Biochem Biophys Res Commun 2002, 299:562-568.

41. Meldolesi J, Pozzan T: Pathways of $\mathbf{C a}+2$ influx at the plasma membrane: Voltage- receptor- and second messenger-operated channels. Exp Cell Res 1987, I 7 I:27I-283.

42. Katz $B$, Miledi $R$ : The effect of calcium on acetylcholine release from motor nerve terminals. Proc R Soc Lond 1965, 16 1:496-502.

43. Basarsky TA, Parpura V, Haydon PG: Hippocampal synaptogenesis in cell culture: developmental time course of synapse formation, calcium influx, and synaptic protein distribution. J Neurosci 1994, 14:6402-64I I.

44. Mattson MP, Kater SB: Calcium regulation of neurite elongation and growth cone motility. J Neurosci 1987, 7:4034-4043.

45. Todorovic SM, Lingle CJ: Pharmacological properties of T-type $\mathrm{Ca}^{+2}$ current in adult rat sensory neurons: effects of anticonvulsant and anesthetic agents. J Neurophysiol 1998, 79:240-252.

46. Todorovic SM, Perez-Reyes E, Lingle C): Anticonvulsants but not general anesthetics have differential blocking effects on different T-type current variants. Mol Pharm 2000, 58:98-108.

47. Liu JH, Bijlenga P, Occhiodoro T, Fischer-Lougheed J, Bader CR, Bernheim L: Mibefradil (Ro 40-5967) inhibits several Ca+2 and K+ currents in human fusion-competent myoblasts. $\mathrm{Br} J$ Pharmacol 1999, 1 26:245-250.

48. McNulty MM, Hanck DA: State-dependent mibefradil block of $\mathrm{Na}^{+}$channels. Mol Pharmacol 2004, 66: 1652-166I.

49. Mills JH, Matthews LI, Lee FS, Dubno JR, Schulte BA, Weber PC Gender-specific effects of drugs on hearing on hearing levels of older persons. Ann N Y Acad Sci 1999, 884:38I-388.

50. Foster TC: Calcium homeostasis and modulation of synaptic plasticity in the aged brain. Aging Cell 2007, 6:319-325.

51. Paschen W, Mengesdorf T: Cellular abnormalities linked to endoplasmic reticulum dysfunction in cerebrovascular disease - therapeutic potential. Pharmacol Ther 2005, 108:362-375.

52. Verkhratsky A: Physiology and pathophysiology of the calcium store in the endoplasmic reticulum of neurons. Physiol Rev 2005, 85:20I-279.

53. Porter NM, Thibault O, Thibault V, Chen K-C, Landfield PW: Calcium channel density and hippocampal cell death with age in long-term culture. J Neurosci 1997, 17:5629-5639.

Publish with Bio Med Central and every scientist can read your work free of charge

"BioMed Central will be the most significant development for disseminating the results of biomedical research in our lifetime. "

Sir Paul Nurse, Cancer Research UK

Your research papers will be:

- available free of charge to the entire biomedical community

- peer reviewed and published immediately upon acceptance

- cited in PubMed and archived on PubMed Central

- yours - you keep the copyright

Submit your manuscript here:

http://www.biomedcentral.com/info/publishing_adv.asp
BioMedcentral 